\title{
Investigation of the suspension of vehicles moving on stone roads
}

\author{
Umar Vakhidov ${ }^{1}$, Vladimir Makarov ${ }^{1,2, *}$, Vladislav Klubnichkin ${ }^{2}$, Evgeny Klubnichkin ${ }^{2}$, \\ and Vladimir Belyakov ${ }^{1}$ \\ ${ }^{1}$ Nizhny Novgorod State Technical University n.a. R.E. Alekseev, 603950, Minina str., 24, Nizhny \\ Novgorod, Russia \\ ${ }^{2}$ Bauman Moscow State Technical University, 105005, $2^{\text {th }}$ Baumanskaya str., 5/1, Moscow, Russia
}

\begin{abstract}
The paper studies the problem of traffic on mountain roads of natural origin. A mathematical model of a natural stone road is presented, the paper demonstrates also diagrams of "floodplain surface vs. support bed slope" correlation function. The calculation of the ride comfort of vehicles utilizes a four-mass model. Calculation results are demonstrated for a GAZ3308 truck, as well as for a vehicle with half the suspension rate. The result obtained shows $30-50 \%$ reduction of the vibration load at a suspension rate reduction by $50 \%$, dependent on the road type. The travel speed can be increased by $45 \%$ dependent on the road type and driver's work time.
\end{abstract}

\section{Introduction}

More than a half of the territory of the Russian Federation is occupied by mountains and highlands. The mountainous regions of Russia concentrate vast and various natural resources. Mountainous territories are living and economic activity areas of numerous nationalities. In order to foster the development of such regions, it is vitally important to assure transport interconnection of all territories of the country. It is specific for many remote mountainous districts that the most scope of cargo transport and handling is performed along floodplains of rivers having specific geometric, physical and mechanical properties. See an example of truck driving on a floodplain of a mountain river in Fig. 1.

The studies by the authors demonstrate that stone roads can be classified as follows [2]:

- by origin (natural and artificial);

- by support bed property (beaten and virgin);

- by boulder size (roads with small stones, roads with stones comparable with the locomotor size, roads with stones comparable with the vehicle size);

- by stone shape (irregular or round shape);

- by presence of water;

- by support bed slope.

\footnotetext{
* Corresponding author: makv12010@gmail.com
} 


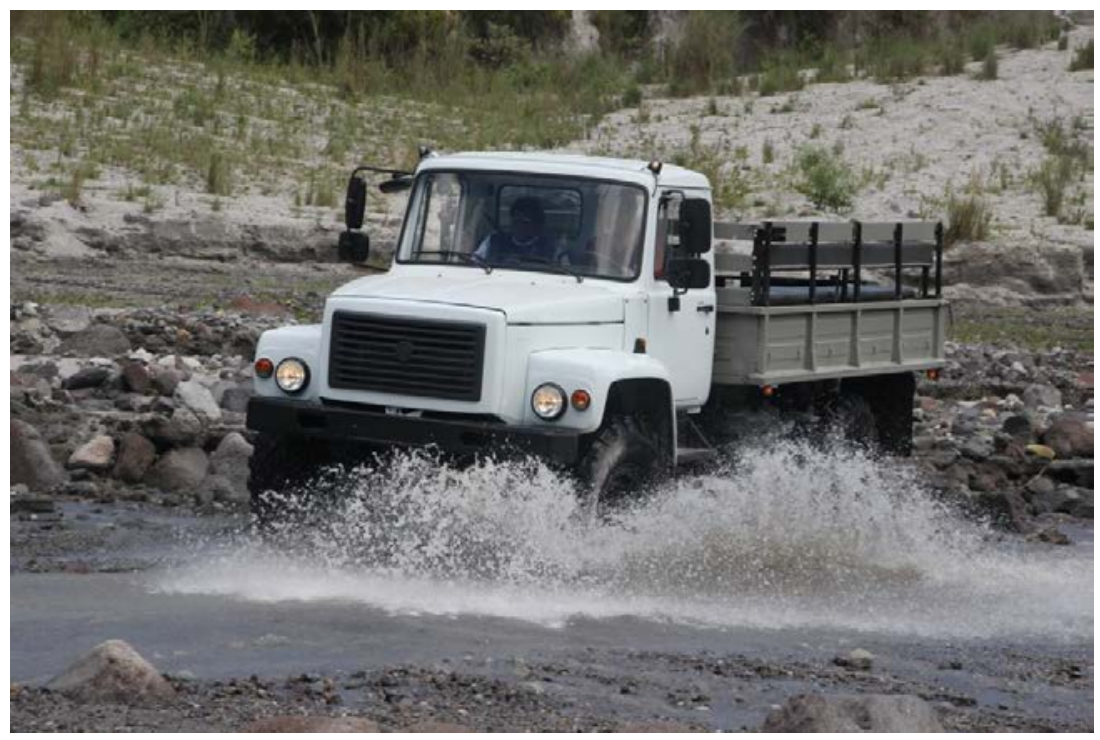

Fig. 1. GAZ-3308 "Sadko" truck driving on a floodplain of a mountain river [1]

It is the support bed slope that influences the stone sizes and the roughness of the road. The greater the support bed slope angle to the horizon, the bigger is the fraction of rocky inclusions. Within the scope of the present paper, the influence of the roughness of stone roads on the ride comfort of automotive vehicles is analyzed.

\section{Mathematical model}

\subsection{Assumptions}

For the calculation of the ride comfort of wheel type vehicles on stone roads we assume the following:

- the geometrical parameters of the support surface are stipulated by round shape stone sizes;

- the sag of the support surface is totally negligible;

- the fraction of the rocky inclusions is determined by the slope angle of the ride surface plane to the horizontal plane, the lower is the slope, the smaller is the size of the boulders;

- a section of the surface of a specific road section is the implementation of the profile, whereas a multitude of such implementations represents the road profile as a random process; - for ride comfort calculation, a four-mass model is used.

\subsection{Mathematical model of stone roads}

As studies [3-5] demonstrate, the probability characteristics of the support surface roughness could be described by $R_{\mathrm{q}}(l)$ correlation function reflecting the probability relationship between the micro-profile coordinates along $l$ way section. Previously, the authors of $[6,7]$ have obtained correlation function values for stone roads with different inclination angles. An example is shown in Fig. 2. 


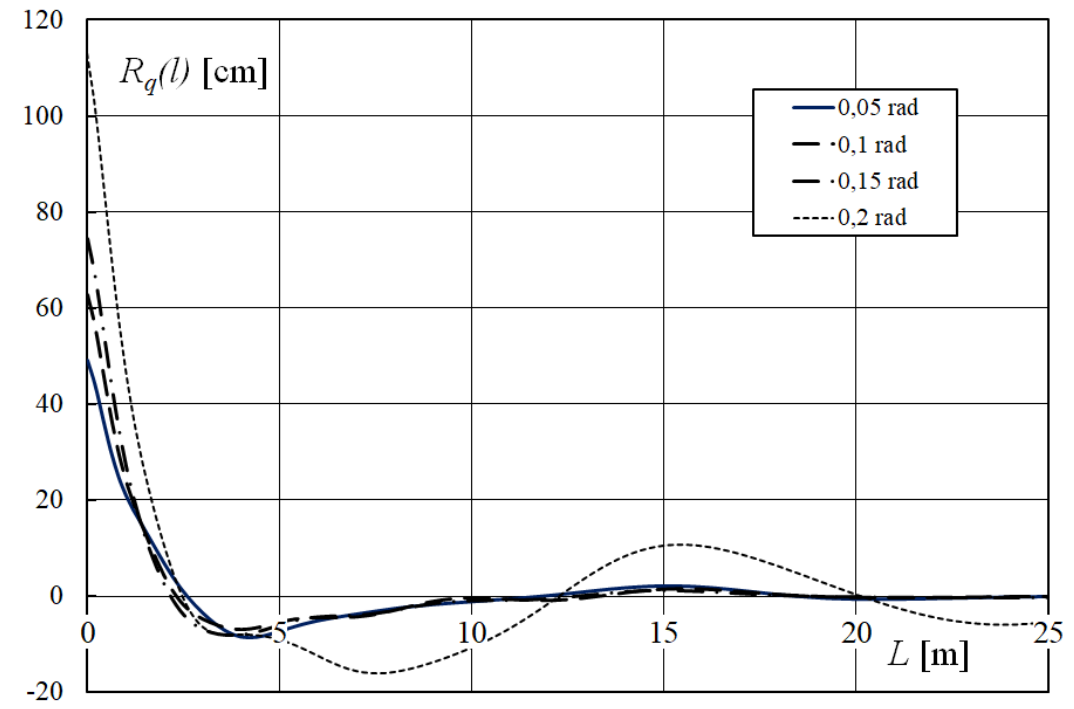

Fig. 2. Correlation function diagram "Floodplain surface roughness vs. support bed inclination angle"

\subsection{Mathematical model of vehicle}

For the ride comfort calculation of vehicles, the calculation diagram for suspension specifications $[8,9]$ is utilized, see Fig. 3.

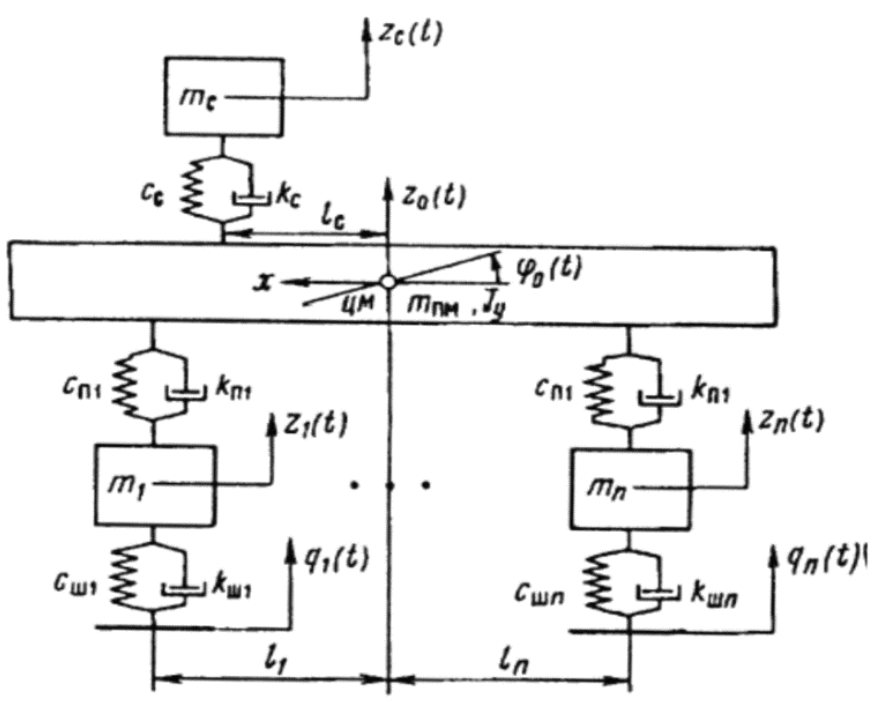

Fig. 3. Calculation diagram for suspension specifications

For ride comfort calculation, the following dependencies were utilized: 


$$
\begin{aligned}
& m_{i} \ddot{z}_{i}+\left(k_{s i}+k_{w i}\right) \dot{z}_{i}+\left(c_{s i}+c_{w i}\right) z_{i}-k_{s i}\left(\dot{z}_{0}+l_{i} \dot{\varphi}_{0}\right)-c_{s i}\left(z_{0}+l_{i} \varphi_{0}\right)=k_{w i} \dot{q}_{i}+c_{w i} q_{i} ; \\
& m_{s m} \ddot{z}_{0}+\dot{z}_{0} \sum_{i=1}^{n} k_{s i}+z_{0} \sum_{i=1}^{n} c_{s i}+\dot{\varphi}_{0} \sum_{i=1}^{n} k_{s i} l_{i}+\varphi_{0} \sum_{i=1}^{n} c_{s i} l_{i}+k_{c}\left(\dot{z}_{0}+l_{c} \dot{\varphi}_{0}\right)+ \\
& +c_{c}\left(z_{0}+l_{c} \varphi_{0}\right)=k_{c} \dot{z}_{c}+c_{c} z_{c}+\sum_{i=1}^{n}\left(k_{s i} \dot{z}_{i}+c_{s i} z_{i}\right) \\
& J_{y} \ddot{\varphi}_{0}+\dot{\varphi}_{0} \sum_{i=1}^{n} k_{s i} l_{i}^{2}+\varphi_{0} \sum_{i=1}^{n} c_{s i} l_{i}^{2}+\dot{z}_{0} \sum_{i=1}^{n} k_{s i} l_{i}+z_{0} \sum_{i=1}^{n} c_{s i} l_{i}+k_{c}\left(\dot{z}_{0}+l_{c} \dot{\varphi}_{0}\right) l_{c}+ \\
& +c_{c}\left(z_{0}+l_{c} \varphi_{0}\right) l_{c}=\left(k_{c} \dot{z}_{c}+c_{c} z_{c}\right) l_{c}+\sum_{i=1}^{n}\left(k_{s i} \dot{z}_{i}+c_{s i} z_{i}\right) l_{i} ; \\
& m_{c} \ddot{z}_{c}+k_{c} \dot{z}_{c}+c_{c} z_{c}=k_{c}\left(\dot{z}_{0}+l_{c} \dot{\varphi}_{0}\right)+c_{c}\left(z_{0}+l_{c} \varphi_{0}\right) .
\end{aligned}
$$

In formulas (1), $z_{0}(t), z_{i}(t), z_{c}(t)$ are generalized coordinates characterizing the vertical travels of the center of mass of the spring borne vehicle part, the mass of the non-cushioned part of the $i^{\text {th }}$ axle, $\phi_{0}(t)$ are generalized coordinates characterizing angular displacement of the spring-borne mass relative to its center of mass; $q_{n}(t)$ is the kinematic disturbance to the $i^{\text {th }}$ axle wheels; $m_{s m}, m_{c}, m_{i}$ are the masses of the spring borne vehicle part, of the seat with a person, of the spring borne part of the $i^{\text {th }}$ axle and the driving axle, respectively; $J_{y}$ is the moment of mass inertia of the spring borne part relative to the transversal axis $y$ passing through its center of mass; $k_{s i}, k_{w i}, k_{c}$ are reduced to the center contact spots of the tire with the support surface (track) damping rates of the suspensions and the tires of the $i^{\text {th }}$ axle, of the seat, $c_{s i}, c_{w i}, c_{c}$ are reduced to the center contact spots of the tire with the support surface (track) suspension rate and stiffness rates of the tires of the $i^{\text {th }}$ axle, and of the seat; $l_{i}$ is the distance from the center of mass of the spring borne part to the $i^{\text {th }}$ axle, $l_{c}$ is the distance from the center of mass of the spring borne part to the seat; $i$ is the axle number; $n$ is the number of the axles.

\section{Calculation results}

In order to define the disturbing impact $q_{n}(t)$ in formulas (1), the road roughness with the characteristics specified in Fig. 2 was modeled as a harmonics sum. An example is shown in Fig. 4. 


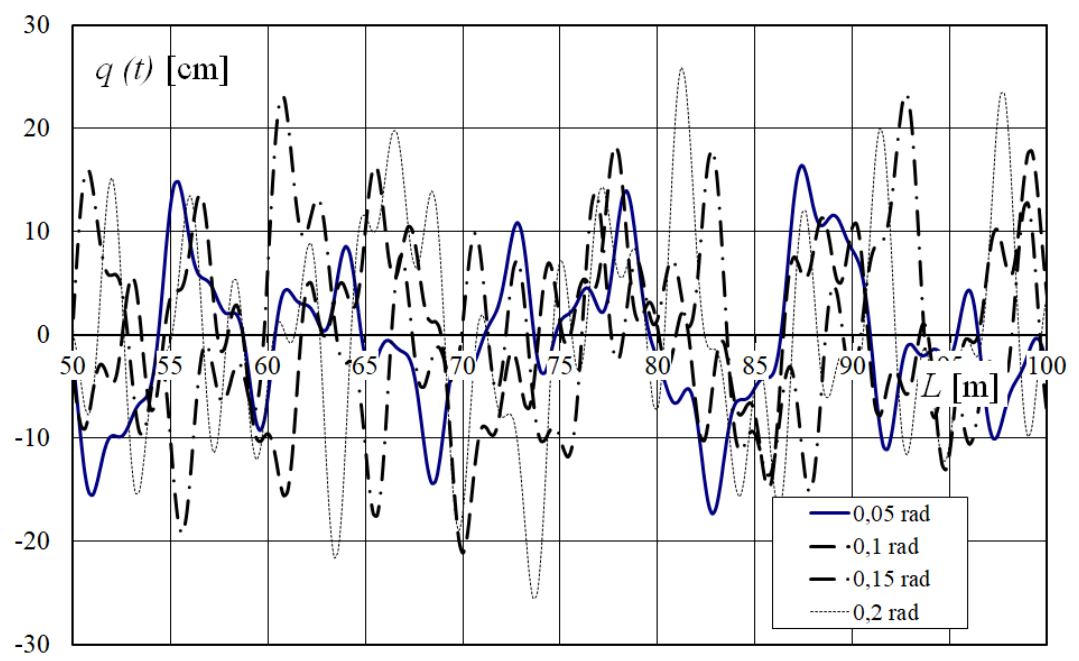

Fig. 4. Stone road roughness example

Based on the roughness data, the calculation diagram in Fig. 3 and formulas (1), we calculate the reduced vibration acceleration values on the driver's seat. In accordance with GOST 12.1. 012 "Vibration safety. General requirements", we determine the admissible driver's work time.

Fig. 5 shows data for a truck with specifications similar to those of GAZ-3308, as well as of a vehicle with half the suspension rate.

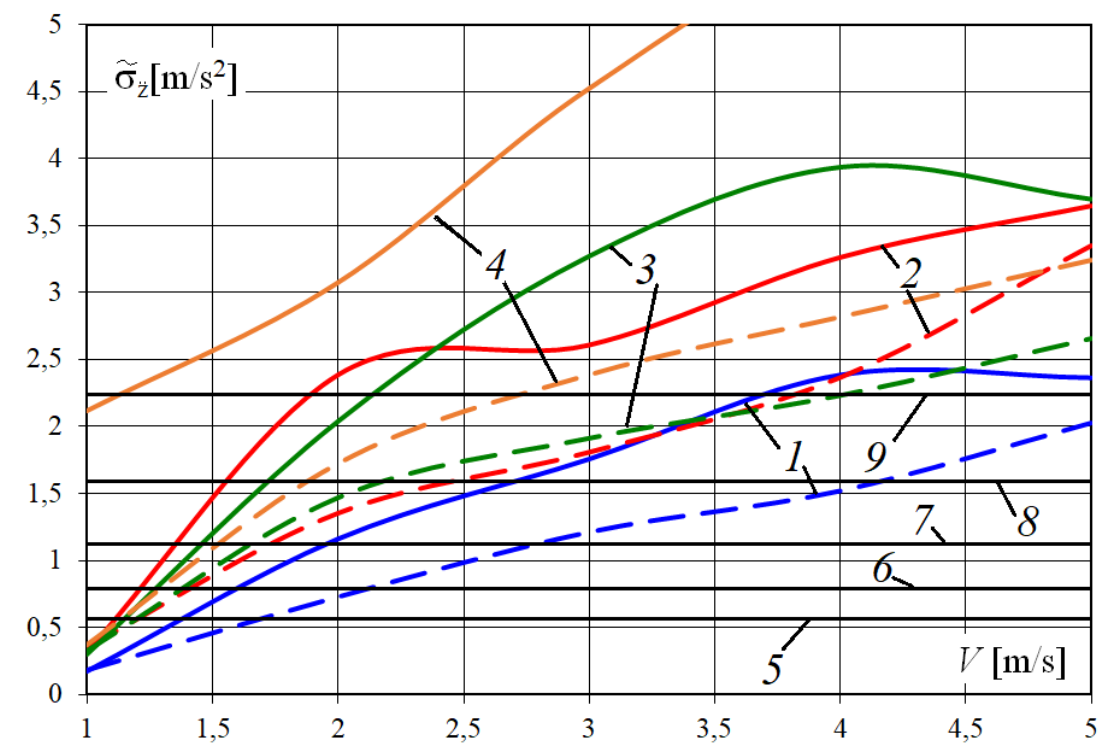

Fig. 5. Diagrams of reduced rms accelerations in driver's seat dependent on the travel speed of GAZ3308 truck on stone roads

Fig. 5 shows dependencies of reduced rms accelerations dependent on the travel speed of a GAZ-3308 truck on stone roads with different slope angles to the horizon. Solid lines represent the standard suspension of the truck, the dashed lines represent represents a suspension with half the suspension rate. The numbers show rms accelerations for roads with 
different slope rates: $1-0.05 \mathrm{rad}, 2-0.10 \mathrm{rad}, 3-0.15 \mathrm{rad}, 4-0.20 \mathrm{rad}$. The horizontal lines indicate the rated work time values: $5-8 \mathrm{hrs}, 6-4 \mathrm{hrs}, 7-2 \mathrm{hrs}, 8-1 \mathrm{hr}, 9-0.5 \mathrm{hr}$.

\section{Conclusions}

The paper presents mathematical models describing the roughness of stone roads and the ride comfort of vehicles. Based on such models, calculations were made for assessment of the influence of the suspension rate on driver's work time. The obtained admissible speed values for GAZ-3308 trucks on stone roads are: 1.4-3.7 m/s with standard suspension and 1.7-5.4 $\mathrm{m} / \mathrm{s}$ with a suspension with half the suspension rate on $0.05 \mathrm{rad}$ slope; $1.1-1.9 \mathrm{~m} / \mathrm{s}$ with standard suspension and $1.2-3.8 \mathrm{~m} / \mathrm{s}$ with a suspension with half the suspension rate on 0.10 rad slope; $1.15-2.12 \mathrm{~m} / \mathrm{s}$ with standard suspension and $1.2-4.05 \mathrm{~m} / \mathrm{s}$ with a suspension with half the suspension rate on $0.15 \mathrm{rad}$ slope; less than $1.15 \mathrm{~m} / \mathrm{s}$ with standard suspension and $1.15-2.75 \mathrm{~m} / \mathrm{s}$ with a suspension with half the suspension rate on $0.20 \mathrm{rad}$ slope (the less value applies to $8 \mathrm{hrs}$ driver's work time, the greater value applies to $0.5 \mathrm{hrs}$ driver's work time). The analysis the obtained data demonstrates $30-50 \%$ reduction of the vibration load at a suspension rate reduction by $50 \%$, dependent on the road type. The travel speed can be increased by $45 \%$ dependent on the road type and driver's work time.

The results of the given study have been obtained with financial support of the grants of the President of the Russian Federation № MD-226.2020.8.

\section{References}

1. Enjoying Rough Pinatubo Roads with GAZ Sadko (URL: https://wheels.com.ph/enjoying-rough-pinatubo-roads-with-gaz-sadko/)

2. V.S. Makarov, K.O. Goncharov, V.V. Belyakov, Mathematical modeling of vehicle drive traces on roads of "stone road" type, Proceedings of the Academy of Engineer Sciences n.a. A.M. Prokhorov, 1, P. 129-134 (2011)

3. N.N. Yatsenko, O.K. Prutchikov, Ride comfort of trucks (Moscow, Machine-building, 1969)

4. G.B. Bezborodova, V.G. Galushko, Locomotion modeling of a motor vehicle (Kiev, "Vischa Shkola", 1978)

5. V.I. Yershov, L.V. Barakhtanov, Probability characteristics of terrain roughness, Proceedings of Institutions of Higher Education. Machine-building, 4, p. 117-119 (1971)

6. U.Sh. Vakhidov, V.S. Makarov, V.V. Belyakov, Determining of roughness specifications in river floodplains of the Northern Caucasus, Smart systems in manufacturing, 1, p. 82-87 (2011)

7. U.Sh. Vakhidov, V.S. Makarov, V.V. Belyakov, Mathematical description of roads of "stone road" type, Contemporary problems of science and education, 3; URL: www.science-education.ru/103-6376 (2012)

8. N. F. Bocharov, I. S. Tsitovich, A.A. Polungyan, Design and calculation of off-road capable wheel type motor vehicles (Moscow, Machine-building, 1983)

9. A.A. Polungyan, Design of all-wheel drive vehicles (Bauman MSTU 2008) 